\title{
Electrochemical Response of a Vitreous Carbon Electrode Modified by a Thiomacrocyclic Compound Film
}

\author{
E. Guaus, ${ }^{*}$ J. Torrent-Burgués \\ Department of Chemical Engineering, Universitat Politècnica de Catalunya, C/ Colom, 1, \\ 08222-Terrassa, Spain
}

\begin{abstract}
A Langmuir-Schaefer (LS) film of a thiomacrocyclic (ThM) compound was deposited on the surface of a glassy carbon electrode (GCE) rod, from a subphase containing $\mathrm{Cu}(\mathrm{II})$ ions. The voltammetric response of this modified GCE when the ThM was bonded to $\mathrm{Cu}^{2+}$, showed that the LS film moved the oxidation peaks of copper to more positive values. On the other hand, a LS film of the ThM compound was deposited on the surface of a GCE rod from a subphase of pure water. When the voltammetric response of the GCE-ThM electrode was studied in a $\mathrm{Cu}^{2+}-\mathrm{SO}_{4}{ }^{2-}$ solution, it was found that the modified electrode increases its sensitivity respect to $\mathrm{Cu}^{2+}$ at low bulk $\mathrm{Cu}^{2+}$ concentrations in solution, and a surface-complexation reaction is proposed to explain the effect of the LS film on the GCE surface.
\end{abstract}

Keywords: modified electrodes, Langmuir-Schaefer films, cyclic voltammetry, surfacecomplexation reaction.

\section{Introduction}

Langmuir-Blodgett (LB) and Langmuir-Schaefer (LS) film formation are techniques used to deposit organized thin films on surfaces $[1,2]$. The LB technique can create monolayer and multilayer structures with large-scale order and this technique has been used to fabricate modified electrodes at the nanometric scale [3], with potential applications in sensors and optical and electronic devices. The LB technique can also provide new insight into electron transfer reactions at interfaces [4-9]. The LS technique, i.e. horizontal deposition, has also been employed for transferring monolayers onto substrates [10].

\footnotetext{
* Corresponding author. E-mail address: ester.guaus @ upc.edu
} 


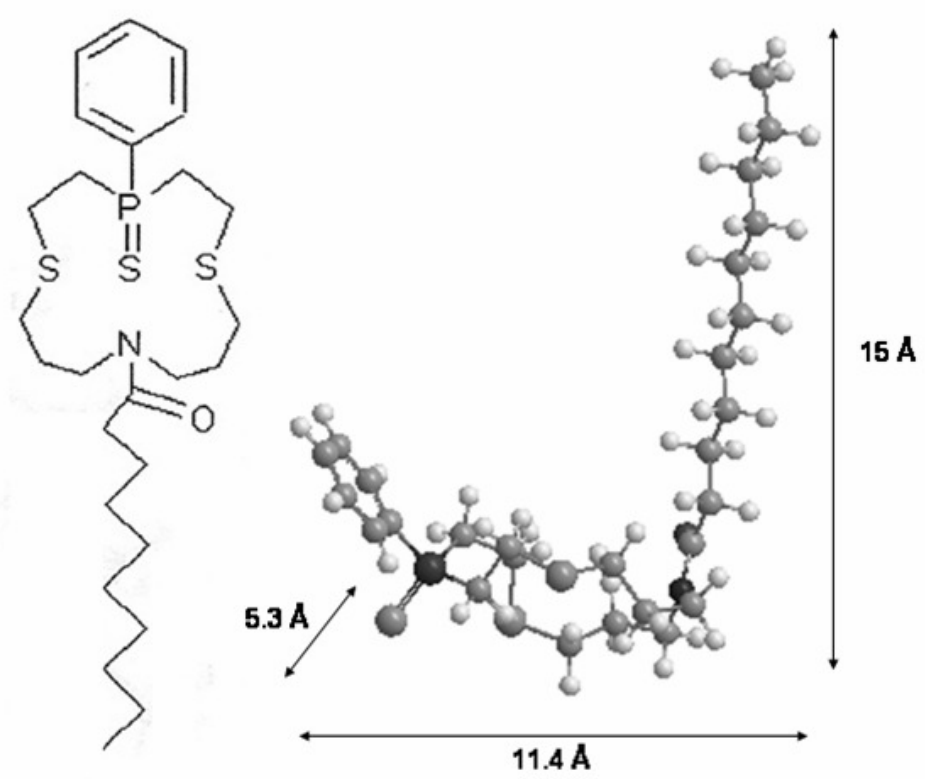

Figure 1. Thiomacrocycle (ThM) 4-phenil-4-sulfide-11-(1-oxodecyl)-1,7-dithia-11-aza4-phosphaciclotetradecane.

In this work we used the LS technique to modify the surface of vitreous carbon electrodes with films of this new thiomacrocyclic compound bonded or not to $\mathrm{Cu}$ (II) ions. The aim of this paper is to characterize these modified electrodes studying their voltammetric response to $\mathrm{Cu}(\mathrm{II})$ ions in a sulphate medium and to compare this electrochemical response with that obtained for a bare vitreous carbon electrode (GCE). This electrochemical response is also compared to that obtained when a thicker coating is deposited on the GCE surface. The application of a GCE modified with a LS film of the thiomacrocycle as amperometric sensor of $\mathrm{Cu}$ (II) ions is also tested.

\section{Experimental}

\section{Langmuir-Schaefer film formation}

The thiomacrocyclic compound was synthesized as described previously [11]. This compound forms stable Langmuir and Langmuir-Blodgett films [11]. Langmuir films were obtained in a NIMA 1232D1D2 trough placed on an isolation platform. Pure water, Millipore MilliQ grade (resistivity of $18 \mathrm{M} \Omega \mathrm{cm}$ ), and solutions of copper(II) nitrate (from analytical reagent $\mathrm{Cu}\left(\mathrm{NO}_{3}\right)_{2}$ and MilliQ water) were used as subphases. A volume of $50 \mu \mathrm{L}$ of a solution of the compound in chloroform, at a concentration of $1 \mathrm{mg} / \mathrm{mL}(1.9 \mathrm{mM})$, was spread over the corresponding subphase, and there was a $15 \mathrm{~min}$ lag before measurements in order to permit evaporation of the solvent. The compression speed was of $50 \mathrm{~cm}^{2} \mathrm{~min}^{-1}$, that is $2.5 \mathrm{~cm} \mathrm{~min}^{-1}$, that is $8.5 \AA^{2}$ molecule $\mathrm{min}^{-1}$. The surface pressure was measured using the Wilhelmy method incorporated to the NIMA trough and a paper sheet. The Langmuir-Schaefer (LS) films (see scheme 1) were transferred at constant pressure onto a clean vitreous carbon rod, of $0.0314 \mathrm{~cm}^{2}$ area, for electrochemical measurements. The transfer was done 
from the corresponding films on water, using a NIMA 1232D1 dipper, at several surface pressures and at $21^{\circ} \mathrm{C}$.

LS: Langmuir-Schaefer

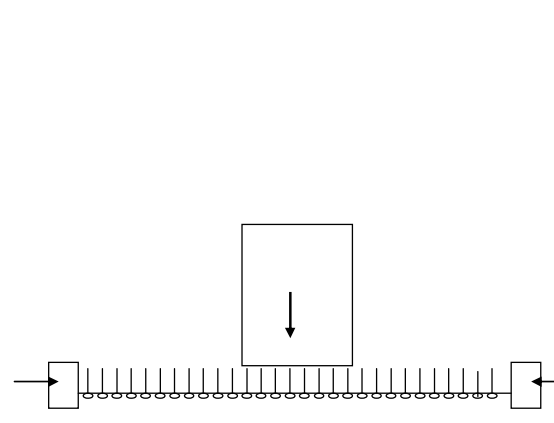

(1)
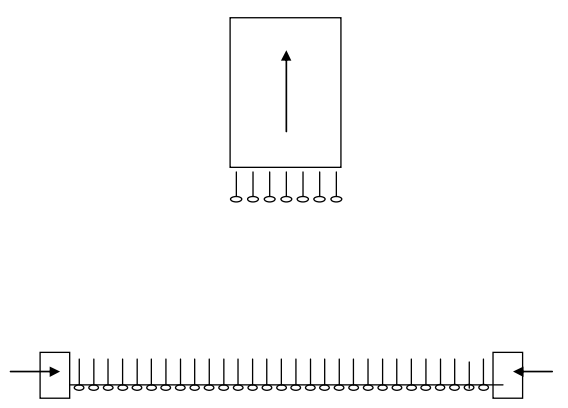

(2)

Scheme (1)

\section{Coating technique}

Also thicker coatings were obtained by spreading a drop of the thiomacrocyclic compound solution in chloroform onto the electrode surface, and letting the solvent evaporate. From the drop volume, concentration solution, molecular area and electrode surface, the multilayer thickness was estimated.

\section{Electrochemical measurements}

The electrochemical measurements were performed in a conventional threeelectrode cell using a microcomputer-controlled AUTOLAB PSTAT 20 potentiostat/galvanostat implemented with a low current module from Eco Chemie. Vitreous carbon rod (GCEr) was used as the working electrode. The reference electrode was an $\mathrm{Ag} / \mathrm{AgCl} / 1 \mathrm{M} \mathrm{NaCl}$ electrode mounted in a Luggin capillary containing $\mathrm{Na}_{2} \mathrm{SO}_{4}$ solution at the same concentration as in the bath. All potentials refer to this electrode. The counter electrode was a platinum spiral. The electrochemical measurements were performed at room temperature, $21^{\circ} \mathrm{C}$. Voltammetric experiments were carried out at $50 \mathrm{mV} \mathrm{s}^{-1}$, scanning towards negative potentials. Inside the experimental cell, a conditioning potential of 250 $\mathrm{mV}$ was applied on the working electrode during $20 \mathrm{~s}$ before the experiments started.

The surface of the working electrode was thoroughly prepared before an electrochemical experiment or before the formation of a thiomacrocycle film. The vitreous carbon rod electrode of $0.0314 \mathrm{~cm}^{2}$ area, from Metrohm, was polished to a mirror finish using alumina of different grades $(3.75$ and $1.85 \mu \mathrm{m})$, and cleaned ultrasonically for $2 \mathrm{~min}$ in water. To clean the working electrode 
surface after their modification by a thiomacrocycle film, it was polished with $\mathrm{SiC}$ paper and alumina of different grades.

The chemicals used were $\mathrm{CuSO}_{4} .5 \mathrm{H}_{2} \mathrm{O}$ and $\mathrm{Na}_{2} \mathrm{SO}_{4}$, all of analytical grade. All solutions were freshly prepared with water that had been distilled and then treated with a Millipore Milli Q system. In the experiments with the vitreous carbon rod electrode modified with a LS film of thiomacrocycle bonded to $\mathrm{Cu}^{2+}$ $\left(\mathrm{Cu}^{2+}-\mathrm{ThM}\right)$, the electrochemical cell contained $0.1 \mathrm{M} \mathrm{Na}_{2} \mathrm{SO}_{4}$ at the $\mathrm{pH}$ of the salt (4.95). In the other experiments the electrochemical cell contained $0.1 \mathrm{M}$ $\mathrm{Na}_{2} \mathrm{SO}_{4}$ as the supporting electrolyte and aliquots of $\mathrm{CuSO}_{4}$ were pipetted into the cell from a $0.5 \mathrm{M} \mathrm{CuSO}_{4}$ solution. The total $\mathrm{Cu}^{2+}$ ion bulk concentration in solution, $\mathrm{c}_{\mathrm{Cu}}$, was varied from $0.01 \mathrm{mM}$ to $10 \mathrm{mM}$. The measured $\mathrm{pH}$ of the cell oscillated between 5-5.5. Before the experiments, and after each new $\mathrm{CuSO}_{4}$ addition, the solutions were de-aerated with argon. The $\mathrm{Cu}^{2+}$ ion was soluble in solution in the interval of concentrations studied.

\section{Results}

\section{Langmuir films formation and surface pressure-area isotherms}

Fig. 2 shows the surface pressure-area isotherms for the Langmuir films of the studied ThM compound, in both a water subphase and a $0.05 \mathrm{M}$ copper(II) aqueous solution subphase. The isotherms show the influence of copper(II) ions on the ThM film. The deposition surface pressures for the LS films, which are 12 $\mathrm{mNm}^{-1}$ for the pure water subphase and $22 \mathrm{mNm}^{-1}$ for the copper(II) aqueous solution subphase, are also indicated with arrows in Fig. 2.

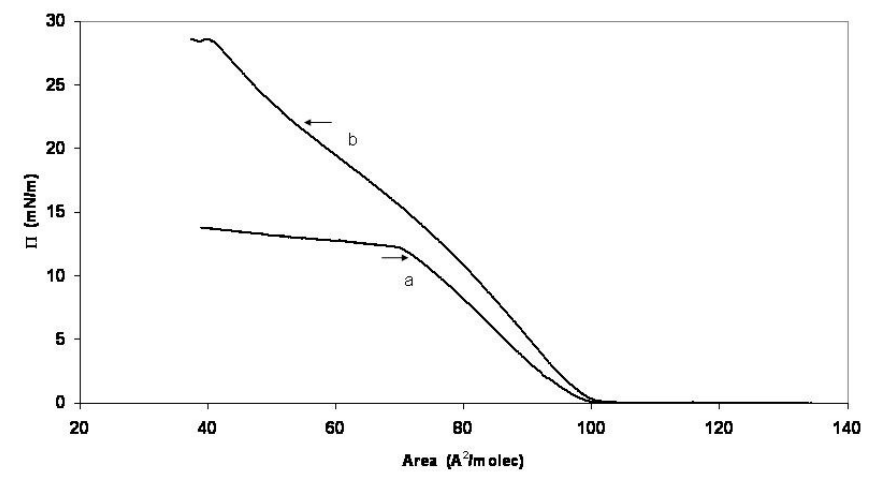

Figure 2. Surface pressure - area per molecule isotherms at different subphases: a) pure water; b) $0.05 \mathrm{M}$ copper(II) aqueous solution. Arrows indicate deposition surface pressures for LS films: a) $12 \mathrm{mNm}^{-1}$; b) $22 \mathrm{mNm}^{-1}$. 


\section{Voltammetric experiments}

Vitreous carbon electrode rod modified with LS films of $\mathrm{Cu}^{2+}-\mathrm{ThM}$

Fig. 3 shows the electrochemical response, in a $0.1 \mathrm{M} \mathrm{Na}_{2} \mathrm{SO}_{4}$ electrolyte solution, of the vitreous carbon rod electrode without modification (curve a) and modified with a LS film of the ThM transferred from a $0.05 \mathrm{M}$ subphase of $\mathrm{Cu}^{2+}$ ions at a surface pressure $\pi=22 \mathrm{mNm}^{-1}$ (curve c). A weak electrochemical reduction wave and a double oxidation wave, peaks $I I_{o}$ and $I_{o}{ }_{o}$, are obtained with a peak potential of $E_{p}\left(I_{o}^{\prime}\right)=150 \mathrm{mV}$. This response does not change with repeated cycling. Curve $b$ shows the behavior of the vitreous carbon electrode rod immersed in the same solution subphase, but without the Langmuir film of the ThM. This procedure has been used to test if $\mathrm{Cu}^{2+}$ ions can be adsorbed on the vitreous carbon electrode surface. After the extraction, the electrode surface is cleaned by immersion in purified water three times, and immersed in the electrolyte solution. Curve $\mathrm{b}$ shows that despite cleaning the electrode surface, some $\mathrm{Cu}^{2+}$ ions remain adsorbed on the electrode giving a reduction peak, $I_{r}$, at a potential of $E_{p}\left(I_{r}\right)=-100 \mathrm{mV}$ and an oxidation wave with an oxidation peak, labeled as $I I_{o}+I_{o}$, at a potential of $E_{p}\left(I I_{o}+I_{o}\right)=-40 \mathrm{mV}$. This response does not change with repeated cycling. From the charge calculated below the oxidation peak $I I_{o}+I_{o}$, an electrode surface coverage of $0.3 \%$ can be calculated. The same calculus below the oxidation peak $I_{o}^{\prime}$, taking into account the projected geometrical area of the thyomacrocycle molecule, $40 \AA^{2}$ [11], gives $14 \%$ coverage of $\mathrm{Cu}^{2+}$ on the surface of the modified GCEr. This result implies a ratio of $0.14 \mathrm{Cu}^{2+}$ ions per ThM molecule in the LS film.

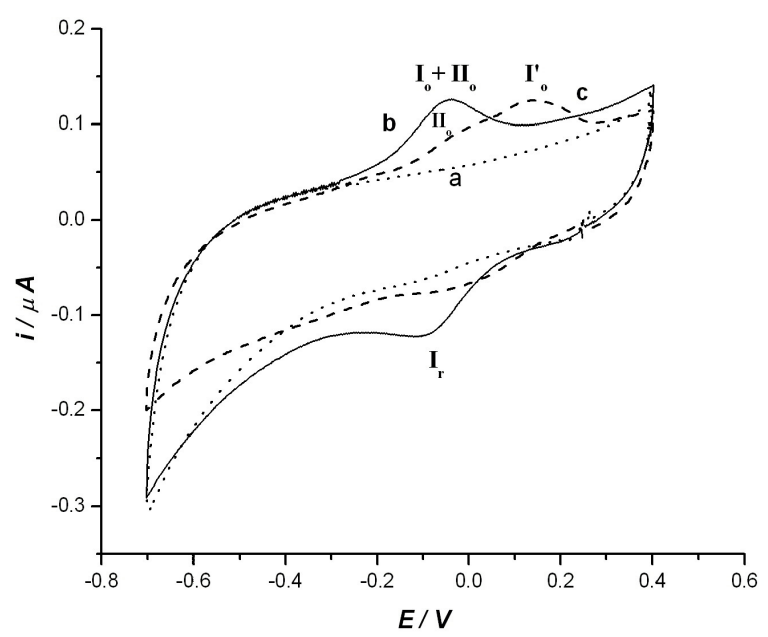

Figure 3. Cyclic voltammograms at $50 \mathrm{mV} \mathrm{s}^{-1}$ in a $0.1 \mathrm{M} \mathrm{Na}_{2} \mathrm{SO}_{4}$ solution on: a) GCE rod (dotted line); b) GCE rod with adsorbed $\mathrm{Cu}^{2+}$ (solid line), and c) GCE rod modified with a LS film of $\mathrm{Cu}^{2+}-\mathrm{ThM}$ (dashed line).

Vitreous carbon electrode rod modified with LS films of ThM (GCEr-ThM)

The curves $\mathrm{a}$ and $\mathrm{b}$ in Fig. 4-7 compare the voltammetric response of the bare GCEr and GCEr-ThM when aliquots of $\mathrm{CuSO}_{4}$ are added into the electrolyte cell solution. The LS film of the ThM was transferred from a subphase of pure water at a surface pressure $\pi=12 \mathrm{mNm}^{-1}$. The electrochemical reduction wave of $\mathrm{Cu}^{2+}$ 
ions on the bare GCEr at the lowest concentration studied (Fig. 4, curve a) presents one reduction peak, $I_{r}$ and two oxidation peaks, $I I_{o}$ and $I_{o}$ (see Table 1 for the peak potential values). When the total bulk concentration of $\mathrm{Cu}^{2+}$ increases (Fig. 5 and 6, curves a), a second reduction peak, $I I_{r}$, appears and in the anodic scan peak $I I_{o}$ becomes more important than peak $I_{o}$. The study of the $i_{p}$ dependency vs. the scan rate at $\mathrm{c}_{\mathrm{Cu}}=0.01 \mathrm{mM}$ showed a linear dependency for $i_{p}\left(I_{r}\right)$ and $v<100 \mathrm{mVs}^{-1}$. Cyclic voltammetric experiments made at different potential limits in the forward scan, for $\mathrm{c}_{\mathrm{Cu}}$ in solution between 0.1-10 mM, have shown that only the second reduction peak $I I_{r}$ corresponds to an electrodeposition process, giving the typical nucleation loop of current intensity [14].

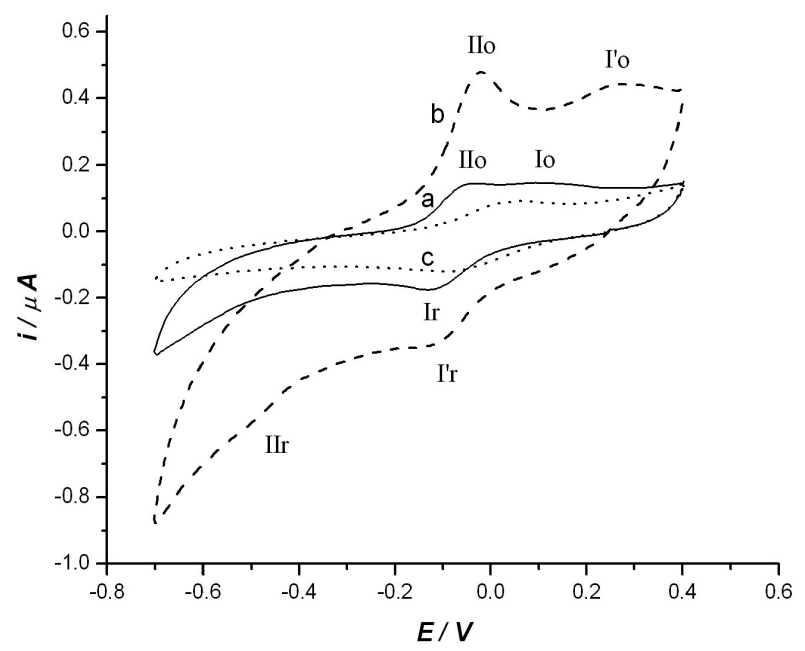

Figure 4. Cyclic voltammograms at $50 \mathrm{mV} \mathrm{s}^{-1}$ in a $0.1 \mathrm{M} \mathrm{Na}_{2} \mathrm{SO}_{4}+0.01 \mathrm{mM} \mathrm{CuSO}_{4}$ solution of a : a) GCE rod (solid line); b) GCE rod modified with a LS film of ThM (dashed line); c) GCE rod modified with a coating of ThM (dotted line).

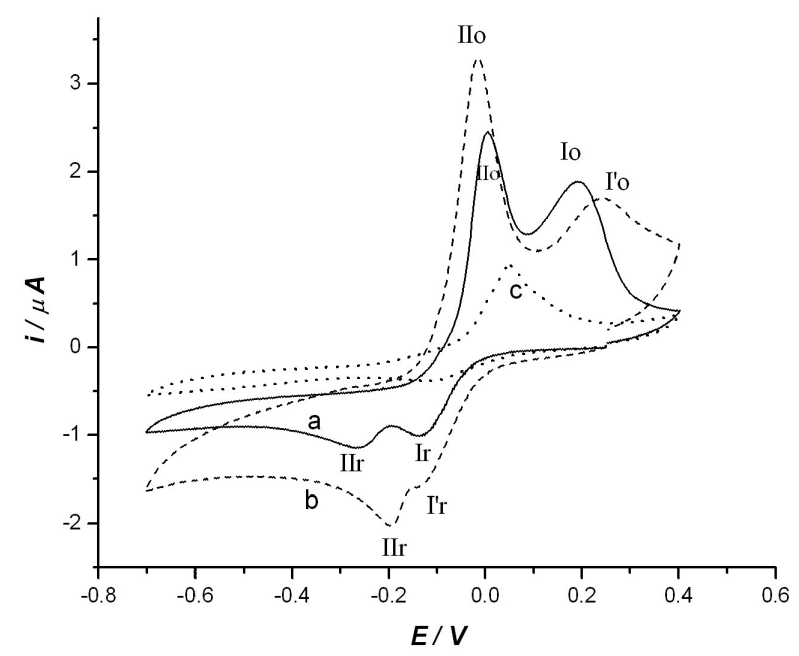

Figure 5. Cyclic voltammograms at $50 \mathrm{mV} \mathrm{s}^{-1}$ in a $0.1 \mathrm{M} \mathrm{Na}_{2} \mathrm{SO}_{4}+0.1 \mathrm{mM} \mathrm{CuSO}_{4}$ solution of a: a) GCE rod (solid line); b) GCE rod modified with a LS film of ThM (dashed line); c) GCE rod modified with a coating of ThM (dotted line). 


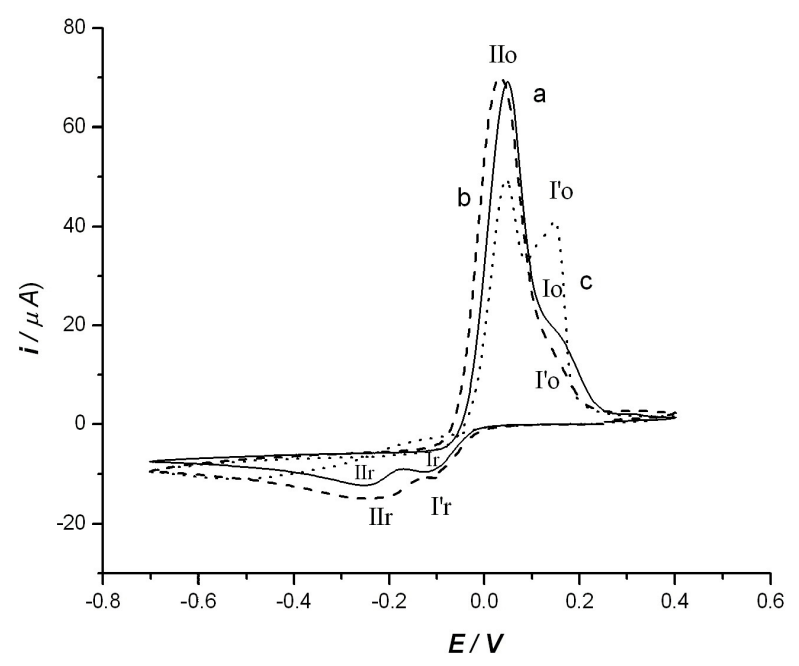

Figure 6. Cyclic voltammograms at $50 \mathrm{mV} \mathrm{s}^{-1}$ in a $0.1 \mathrm{M} \mathrm{Na}_{2} \mathrm{SO}_{4}+1 \mathrm{mM} \mathrm{CuSO}_{4}$ solution of a: a) GCE rod (solid line); b) GCE rod modified with a LS film of ThM (dashed line); c) GCE rod modified with a coating of ThM (dotted line).

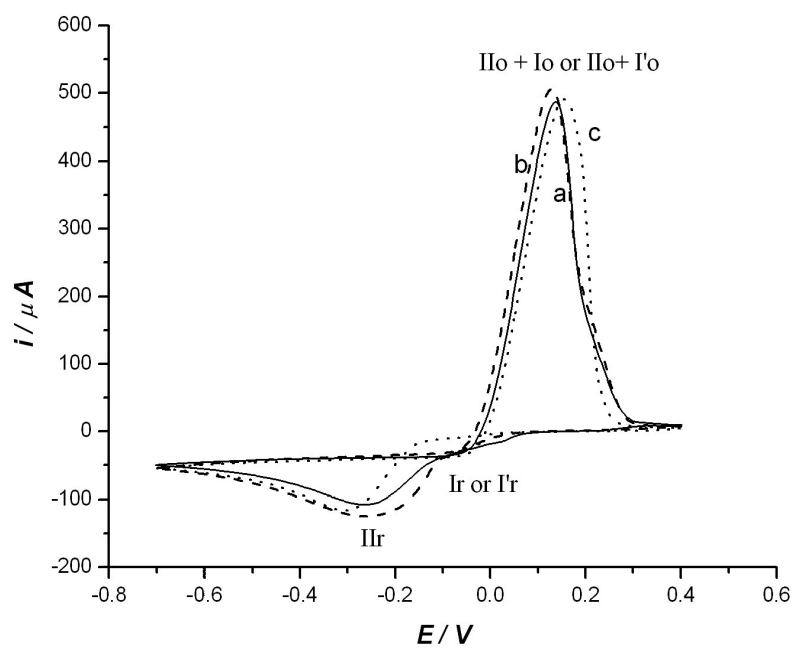

Figure 7. Cyclic voltammograms at $50 \mathrm{mV} \mathrm{s}^{-1}$ in a $0.1 \mathrm{M} \mathrm{Na}_{2} \mathrm{SO}_{4}+10 \mathrm{mM} \mathrm{CuSO}_{4}$ solution of a: a) GCE rod (solid line); b) GCE rod modified with a LS film of ThM (dashed line); c) GCE rod modified with a coating of ThM (dotted line).

The current intensity of the electrochemical response of $\mathrm{Cu}^{2+}$ ions on the GCErThM electrode shows an important increase at the lowest $\mathrm{c}_{\mathrm{Cu}}$ studied (Fig. 4, curve b) and two reduction waves are obtained, $I_{r}{ }_{r}$ and $I I_{r}$. In the reverse scan two oxidation peaks, $I I_{o}$ and $I_{o}$, are obtained as for the bare electrode, but the second one presents an oxidation peak potential, $E_{p}\left(I_{o}{ }_{o}\right)$, more positive than for the bare electrode (see Table 1). When the total bulk concentration of $\mathrm{Cu}^{2+}$ ions in solution increases, (Fig. 5-7, curves b), $E_{p}\left(I I_{r}\right.$ ) moves to more positive potentials and the wave $I I_{r}$ becomes more important than the wave $I_{r}^{\prime}$. In the reverse scan, two oxidation peaks, $I I_{o}$ and $I_{o}$, are obtained at the potentials shown in Table 1 
with $E_{p}\left(I I_{o}\right)$ moving to more positive values when $\mathrm{c}_{\mathrm{Cu}}$ increases. The current intensity of the electrochemical response of $\mathrm{Cu}$ (II) ions on the modified electrode is higher than on the bare electrode at the lowest $\mathrm{c}_{\mathrm{Cu}}$, but tends to be equal at $\mathrm{c}_{\mathrm{Cu}}$ $\geq 1 \mathrm{mM}$.

Table 1. Peak potentials.

\begin{tabular}{|c|c|c|c|c|c|c|c|}
\hline$\left[\mathrm{Cu}^{2+}\right]$ & Electrode & $\mathrm{E}\left(\mathrm{I}_{\mathrm{r}}\right)$ & $\mathrm{E}\left(\mathrm{I}_{\mathrm{r}}^{\prime}\right)$ & $\mathrm{E}\left(\mathrm{II}_{\mathrm{r}}\right)$ & $\mathrm{E}\left(\mathrm{II}_{\mathrm{o}}\right)$ & $\mathrm{E}\left(\mathrm{I}_{\mathrm{o}}\right)$ & $\mathrm{E}\left(\mathrm{I}_{\mathrm{o}}\right)$ \\
\hline \multirow{2}{*}{$1 \times 10^{-5} \mathrm{M}$} & GCEr & $-120 \mathrm{mV}$ & & & $-45 \mathrm{mV}$ & $108 \mathrm{mV}$ & \\
\cline { 2 - 9 } & GCEr+ThM & & $-126 \mathrm{mV}$ & $-430 \mathrm{mV}$ & $-16 \mathrm{mV}$ & & $280 \mathrm{mV}$ \\
\hline \multirow{2}{*}{$1 \times 10^{-4} \mathrm{M}$} & GCEr & $-130 \mathrm{mV}$ & & $-262 \mathrm{mV}$ & $10 \mathrm{mV}$ & $196 \mathrm{mV}$ & \\
\cline { 2 - 9 } & GCEr+ThM & & $-140 \mathrm{mV}$ & $-200 \mathrm{mV}$ & $-11 \mathrm{mV}$ & & $245 \mathrm{mV}$ \\
\hline \multirow{2}{*}{$1 \times 10^{-3} \mathrm{M}$} & GCEr & $-120 \mathrm{mV}$ & & $-250 \mathrm{mV}$ & $52 \mathrm{mV}$ & $150 \mathrm{mV}$ & \\
\cline { 2 - 9 } & GCEr+ThM & & $-120 \mathrm{mV}$ & $-238 \mathrm{mV}$ & $37 \mathrm{mV}$ & & $152 \mathrm{mV}$ \\
\hline
\end{tabular}

Vitreous carbon electrode rod modified with a coating of ThM

The curves $\mathrm{c}$ in Fig. 4-7 show the voltammograms obtained at increasing $\mathrm{c}_{\mathrm{Cu}}$ in solution, when a thicker thiomacrocyclic coating was deposited on a GCEr following the coating technique described in the experimental section, "coating technique". From the volume deposited, we can calculate that the coating has around 20 layers of the ThM compound, and therefore it has around $20 \mathrm{~nm}$ of thickness [11]. At $0.01 \mathrm{mM}$ and $0.1 \mathrm{mM} \mathrm{Cu}^{2+}$ total bulk concentration (Fig. 4 and 5 , curves c) a weak reduction wave is obtained in the forward scan and a wide oxidation wave in the reverse scan. The current intensity is very low compared with that of the bare electrode. When the $\mathrm{c}_{\mathrm{Cu}}=1 \mathrm{mM}$ (Fig. 6, curve c), a more marked reduction peak, labeled as $\mathrm{II}_{\mathrm{r}}$, is obtained, and two oxidation peaks, $\mathrm{II}_{\mathrm{o}}$ and $\mathrm{I}_{\mathrm{o}}$, appear. At $\mathrm{c}_{\mathrm{Cu}}=10 \mathrm{mM}$ (Fig. 7, curve c), a clear electrodeposition wave $\mathrm{II}_{\mathrm{r}}$ is obtained in the forward scan and a wide oxidation peak $\mathrm{II}_{\mathrm{o}}+\mathrm{I}_{\mathrm{o}}$, appears. In this last case the current intensity of the voltammetric response is close to that of the bare electrode.

\section{Chronoamperometric experiments}

The previous voltammetric results showed in Fig. 4-6 let us design chronoamperometric experiments to compare the response of the bare GCEr and the modified GCEr-ThM electrodes. Series of chronoamperometric experiments were made, measuring the current intensity response when a potential step was applied on the working electrode from an initial potential of $250 \mathrm{mV}$, where faradaic reaction does not take place, to a final potential of $-200 \mathrm{mV}$. Fig. 8 shows the plots of the faradaic current intensity measured after $5 \mathrm{~s}$ of the applied final potential, vs the $\mathrm{c}_{\mathrm{Cu}}$ in solution, for the bare GCEr and the modified GCErThM electrodes. The linearity of both plots is good in the concentration range 
between 0.01-1 mM. The least-squares approximation gives a slope of 0.0025 $\mathrm{mA} / \mathrm{mM}\left(\mathrm{R}^{2}=0.99\right)$ for the bare electrode, and a slope of $0.0045 \mathrm{~mA} / \mathrm{mM}$ $\left(\mathrm{R}^{2}=0.98\right)$ for the modified electrode.

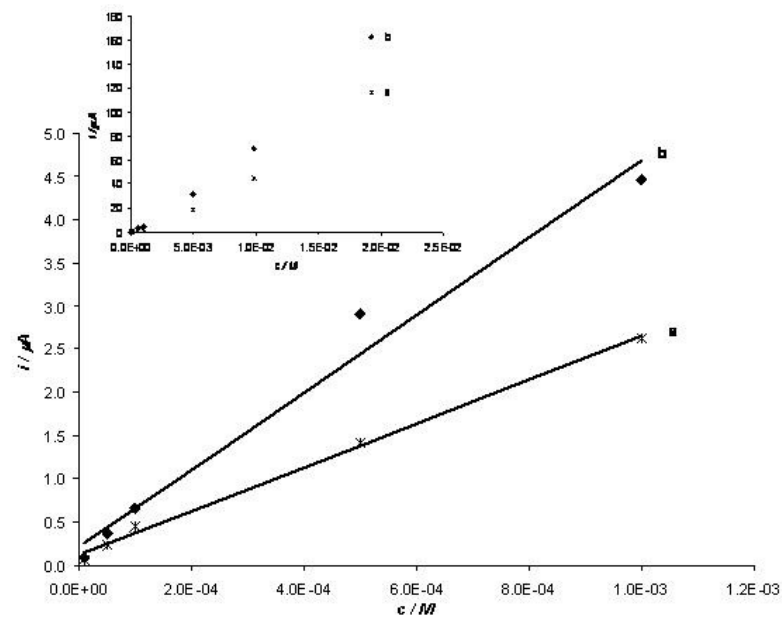

Figure 8. Plot of the faradaic current intensity vs. the total bulk $\mathrm{Cu}^{2+}$ concentration in solution of a: a) GCE rod; b) GCE rod modified with a LS film of ThM. The intensity was measured $5 \mathrm{~s}$ after having applied a step potential from $250 \mathrm{mV}$ to $-200 \mathrm{mV}$.

\section{Discussion and conclusions}

Voltammetric behaviour of the $\mathrm{Cu}^{2+}-\mathrm{SO}_{4}{ }^{2-}$ system on a $\mathrm{GCE}$

The electrochemical behaviour of $\mathrm{Cu}^{2+}$ ion in a sulphate medium depends on the $\mathrm{pH}$, the complexation equilibria in solution and on the interactions with the electrode surface. The sulphate anion is a ligand of $\mathrm{Cu}^{2+}$ ion $\left(\log \mathrm{K}_{1}=2.30\right.$ [15] $)$, but according to the equilibrium diagram of distribution of $\mathrm{Cu}^{2+}$ species in solution vs. the $\mathrm{pH}$ for the $\mathrm{CuSO}_{4}$-water system [16], at $\mathrm{pH}>4$, the formation of copper hydroxyl sulphate complexes in solution, $\mathrm{Cu}_{4}(\mathrm{OH})_{6} \mathrm{SO}_{4}$, is possible specially at $\mathrm{c}_{\mathrm{Cu}}$ higher than $1 \mathrm{mM}$. Also, the formation of the hydroxyl-sulphate complexes will be favoured in the region of positive potentials on the electrode surface, according to the equilibrium $\mathrm{E}\left(\mathrm{Cu} / \mathrm{Cu}^{2+}\right)-\mathrm{pH}$ diagram [16]. At $\mathrm{pH}$ between 5-5.5, we can expect that $\mathrm{Cu}^{2+}$ ion will be present in solution as $\mathrm{CuSO}_{4}$ and/or $\mathrm{Cu}_{4}(\mathrm{OH})_{6} \mathrm{SO}_{4}$ complexes, with $\mathrm{CuSO} 4$ predominating at low $\mathrm{Cu}^{2+}$ ion total bulk concentration.

In this experimental medium, when the total bulk concentration of $\mathrm{Cu}^{2+}$ is very low (0.01 mM in Fig. 4, curve a) the reduction of $\mathrm{Cu}^{2+}$ ions proceeds via the peak $I_{r}$. This peak is the only one obtained in the adsorption test (figure 3, curve b) when only the adsorbed $\mathrm{Cu}^{2+}$ on the bare GCE is reduced. When the concentration of $\mathrm{Cu}(\mathrm{II})$ increases (Fig. 5-7, curves a), the ratio $i_{p}\left(I_{r}\right) / i_{p}\left(I I_{r}\right)$ decreases. As it has been commented in the section "voltammetric experiments", $i_{p}\left(I_{r}\right)$ shows a linear dependence vs. $v$ and only the second reduction peak $I I_{r}$ corresponds to an electrodeposition process. Then, peak $I_{r}$ has the behaviour of 
an adsorption prepeak, i.e, implies the reduction of $\mathrm{Cu}^{2+}$ ion via the formation of an adsorbed product [17].

As it has been proposed by different authors [18 and references cited therein, 19, 20], the formation of a metallic $\mathrm{Cu}$ layer on the electrode surface implies two consecutive charge transfer steps involving the formation of the intermediate $\mathrm{Cu}^{+}$. From our results and in a qualitative way we can represent the reduction of $\mathrm{Cu}$ (II) ions in this medium as:

$$
\begin{gathered}
\mathrm{Cu}^{2+}(\mathrm{sln}) \leftrightarrows \mathrm{Cu}^{2+}(\mathrm{ads})+1 \mathrm{e}^{-} \leftrightarrows \mathrm{Cu}^{+}+1 \mathrm{e}^{-} \leftrightarrows \mathrm{Cu}(\mathrm{GCE}) \text { ads } \\
\mathrm{Cu}^{2+}(\mathrm{sln})+1 \mathrm{e}^{-} \leftrightarrows \mathrm{Cu}^{+}+1 \mathrm{e}^{-} \leftrightarrows \mathrm{Cu}(\mathrm{GCE})
\end{gathered}
$$

Step (1) corresponds to reduction peak $I_{r}$ and implies the adsorption of $\mathrm{Cu}^{2+}$ ions on the electrode surface and its reduction to form an adsorbed copper layer on the GCE surface that precedes the bulk reduction of $\mathrm{Cu}$ (II) ions in solution. As it has been proposed by other authors, the adsorption of $\mathrm{Cu}^{2+}$ ions can be favoured by the formation of $\mathrm{Cu}_{\mathrm{x}} \mathrm{O}$ oxides on the electrode surface [21]. When the concentration of $\mathrm{Cu}^{2+}$ ions in solution is very low, step (1) determines the rate of the whole process. In this situation, peak $I_{r}$ is the main peak obtained in the voltammetric experiments. Then, this first peak is a consequence of the interactions between copper species in solution and the bare electrode surface in the reaction layer, and it is strongly dependent on the pre-treatment of the electrode surface, on the conditioning potential applied on the electrode surface at the beginning of the voltammetric experiment and on the $\mathrm{pH}$ in solution.

Step (2) corresponds to the reduction peak $I I_{r}$ and implies the nucleation and growth of the metallic copper deposit on the surface. When the concentration of $\mathrm{Cu}^{2+}$ ions in solution increases, step (2) becomes the determinant of the rate of the whole process and then peak $I I_{r}$ becomes the main peak.

In the anodic scan (Fig. 3, curve b, and Fig. 4, curve a), the oxidation of metallic $\mathrm{Cu}$ on the GCE proceeds mainly via peak $I_{o}$, by the formation of soluble $\mathrm{Cu}^{2+}$ species in solution:

$$
\mathrm{Cu}(\mathrm{GCE}) \leftrightarrows \mathrm{Cu}^{+}+1 \mathrm{e}^{-} \leftrightarrows \mathrm{Cu}^{2+}(\mathrm{s} \ln )+1 \mathrm{e}^{-}
$$

But the presence of hydroxyl anions in the reaction layer also permits the $\mathrm{Cu}$ oxidation via the formation of oxides or hydroxides, and then peak $I_{o}$ appears. In this case the formation of $\mathrm{Cu}_{\mathrm{x}} \mathrm{O}$ species as intermediate oxidation products can be produced [22]. As the final anodic current does not decay to zero, it is possible that some $\mathrm{Cu}_{\mathrm{x}} \mathrm{O}$ species remain adsorbed on the electrode.

At low total bulk concentration of $\mathrm{Cu}^{2+}$ ions in solution, when the reduction proceeds mainly via peak $I_{r}$, the oxidation process is more reversible, but when the concentration of $\mathrm{Cu}^{2+}$ ions in solution increases, the oxidation process becomes more irreversible (Fig. 5-7 curves a) and $E_{p}\left(I I_{o}\right)$ moves to more positive values and merges with peak $I_{o}$. 
Voltammetric behaviour of the $\mathrm{Cu}^{2+}-\mathrm{SO}_{4}{ }^{2-}$ system on a GCE modified with a LS film of the thiomacrocycle compound (GCEr-ThM)

The analysis of Fig. 3-7, for the GCEr modified with a LS film of the thyomacrocycle reveals that the presence of LS film increases the current of the bare electrode for the reduction of $\mathrm{Cu}^{2+}$ ions in the range of $0.01 \mathrm{mM}-1 \mathrm{mM} \mathrm{c}$. When a thin ThM monolayer (approximately $1 \mathrm{~nm}$ thickness [11]) is deposited on the GCEr surface following a Langmuir-Schaefer extraction, the polar heads of ThM molecules (see scheme 1) becomes oriented to the solution. This permits that a surface complexation reaction can take place on the GCEr-ThM electrode between ThM molecules and the $\mathrm{Cu}^{2+}$ ions in solution. Then, we propose in this case a step (1') to explain peak $I^{\prime}{ }_{r}$ :

$$
\mathrm{Cu}^{2+}(\mathrm{s} \ln ) \leftrightarrows \mathrm{Cu}^{2+}-\mathrm{ThM}+1 \mathrm{e}^{-} \leftrightarrows \mathrm{Cu}^{+}-\mathrm{ThM}+1 \mathrm{e}^{-} \leftrightarrows \mathrm{Cu}(\mathrm{GCE}-\mathrm{ThM})
$$

That is, the formation of the first copper clusters in the GCE-LS layer, promoted by a surface-complexation reaction in the LS layer-solution interface, between ThM molecules and $\mathrm{Cu}^{2+}$ ions. Then, peak $I_{r}{ }_{r}$ behaves as an adsorption pre-peak and the occurrence of this surface-complexation reaction explains the increase of the current density. This step is followed by the same step (2) defined for the bare electrode. Step (2), i.e., the nucleation and growth of the metallic copper layer takes place only when the complexation equilibrium of $\mathrm{Cu}^{2+}$ ions in the $\mathrm{LS}$ layer-solution interface is achieved.

When the total bulk concentration of $\mathrm{Cu}^{2+}$ in solution is very low, the formation of the first copper clusters is slow and it is controlled by the formation of the $\mathrm{Cu}^{2+}-\mathrm{ThM}$ surface-complex. In these cases the current density of modified GCE is higher than for the bare GCE, but peak $I I_{r}$ appears much separated of peak $I_{r}{ }_{r}$ (Fig. 4, curve b). When $\mathrm{c}_{\mathrm{Cu}}$ in solution increases, the surface-complexation reaction is higher and therefore the formation of the first copper clusters is faster, then the control of the process extends more quickly to the solution phase (Fig. 5, curve b), and peak $I I_{r}$ appears closer to peak $\mathrm{I}_{\mathrm{r}}$. When the $\mathrm{c}_{\mathrm{Cu}}$ is high enough, the surface-complexation equilibrium is attained before the electrochemical experiment starts (Fig. 6 and 7, curves b), and then the effects of the LS layer become negligible. In this case, the intensity of the modified electrode tends to that of the bare electrode.

In the anodic wave, two separated oxidation peaks are obtained when the total bulk concentration of $\mathrm{Cu}^{2+}$ in solution is lower than $0.5 \mathrm{mM}$ (Fig. 4 and 5, curves b). We associate the peak $I I_{o}$ with oxidation step (3), i.e., to the formation of soluble $\mathrm{Cu}^{2+}$ species in solution and the peak I' ${ }_{\mathrm{o}}$ with oxidation step (4):

$$
\mathrm{Cu}(\mathrm{GCE}-\mathrm{ThM}) \leftrightarrows \mathrm{Cu}^{+}-\mathrm{ThM}+1 \mathrm{e}^{-} \leftrightarrows \mathrm{Cu}^{2+}-\mathrm{ThM}+1 \mathrm{e}-\leftrightarrows \mathrm{Cu}^{2+}(\mathrm{sln})
$$

that is, the oxidation of metallic copper via the coordination to thiomacrocyclic LS film on the electrode surface. When peak $I^{\prime}{ }_{o}$ appears differentiated from peak $I I_{o}$ the surface-complexation equilibrium $\mathrm{Cu}^{2+}(\mathrm{sln}) \leftrightarrows \mathrm{Cu}^{2+}-\mathrm{ThM}$ in the forward scan hasn't been attained before the experiment starts. When total bulk concentration of $\mathrm{Cu}^{2+}$ in solution increases (Fig. 6 and 7, curves b), peak $I I_{o}$ merges with peak $I_{o}^{\prime}$. As the surface-complexation equilibrium seems to be a 
kinetically slow process, it is possible that some of the $\mathrm{Cu}^{2+}$ formed in the reverse scan remains bonded to ThM molecules in the LS layer.

Voltammetric behaviour of the vitreous carbon electrode rod modified with a coating of ThM

When a thicker thiomacrocyclic coating was deposited on a GCEr, the important decrease of the current at low $\mathrm{c}_{\mathrm{Cu}}$ (Fig. 4 and 5 curves c) reveals that the coating acts as a blocking layer for the ion transport between the bare electrode and the solution. However, as the current intensity increases (Fig. 6, curve b) and tends (Fig. 7, curve c) to that obtained for the bare electrode when the $\mathrm{c}_{\mathrm{Cu}}$ increases, we can consider that a membrane model $[17,23]$ applies to describe the effect of the ThM coating on the electrode surface. In this case permeation equilibrium between ThM coating and solution has to be achieved before the formation of the first copper clusters in the GCE-coating layer can take place. Then, step (1') applies to describe the reduction of $\mathrm{Cu}^{2+}$ ions in the forward scan, but now the equilibrium

$$
\mathrm{Cu}^{2+}(\mathrm{sln}) \leftrightarrows \mathrm{Cu}^{2+}-\mathrm{ThM}
$$

is controlled by the transport of $\mathrm{Cu}^{2+}$ ions across the ThM coating-solution interface (permeation equilibrium). After permeation equilibrium is attained, step (2) can take place, and from our experiments this happens for $\mathrm{c}_{\mathrm{Cu}}$ higher than 0.1 mM. In the reverse scan steps (3) and (4) also apply to describe the oxidation waves. But now the reaction

$$
\mathrm{Cu}^{2+}-\mathrm{ThM}+1 \mathrm{e}-\leftrightarrows \mathrm{Cu}^{2+}(\mathrm{s} \ln )
$$

implies also the permeation across the ThM coating-solution interface. As the permeation seems to be a kinetically slow process [24], it is possible that some of the $\mathrm{Cu}^{2+}$ formed in the reverse scan remains bonded to ThM molecules in the coating layer and permits the permeation equilibrium to be achieved faster when the bulk $\mathrm{Cu}^{2+}$ concentration in solution is increased.

Amperometric behaviour of GCEr-ThM electrode in the $\mathrm{Cu}^{2+}-\mathrm{SO}_{4}{ }^{2-}$ system

We can consider the plots shown in Fig. 8 as calibration plots $[25,26]$ to determine the $\mathrm{Cu}^{2+}$ concentration in solution and, as the sensitivity of the GCErThM is higher than that of the bare electrode, we could consider that the modified GCEr is acting as an amperometric sensor to determine the concentration of $\mathrm{Cu}^{2+}$ ions in solution. But this sensing behaviour does not achieve a plateau $[24,25]$, i.e, a limit of intensity vs. $c_{c u}$ (see the figure inset inside Fig. 8, which is the same plot but when the bulk $\mathrm{Cu}^{2+}$ concentration range is increased until $20 \mathrm{mM}$ ). As it was commented in the discussion of the voltammetric behaviour of the GCEr-ThM electrode, when the surface complexation equilibrium in the LS layer-solution interface is achieved, the 
current intensity of the voltammogram for the GCEr-ThM tends to be equal to that of the GCEr, and then the current intensity will continue increasing with $\mathrm{c}_{\mathrm{cu}}$.

\section{Final conclusions}

The deposition of a Langmuir-Schaefer (LS) film of a thiomacrocyclic compound (ThM), shown in Fig. 1, on the surface of a GCE rod (GCEr) changes its voltammetric response vs. $\mathrm{Cu}^{2+}$ ions, especially at low total bulk concentrations. An increase of the current intensity and a shift of the oxidation peak $I_{o}^{\prime}$ to more positive potentials are obtained when $\mathrm{c}_{\mathrm{cu}} \leq 1 \mathrm{mM}$. The increase of the GCEr-ThM sensitivity with respect to $\mathrm{Cu}^{2+}$ at low bulk $\mathrm{Cu}^{2+}$ concentrations in solution is explained by a surface-complexation reaction in the LS layer-solution interface, between ThM molecules and $\mathrm{Cu}^{2+}$ ions, which promotes the formation of the first $\mathrm{Cu}$ clusters in the GCEr-LS layer. This surface-complexation equilibrium also explains the voltammetric behaviour of the vitreous carbon electrode when a thick coating of the thiomacrocycle is deposited on its surface. The amperometric study also shows that the sensitivity of the GCEr-ThM is higher than that of a bare electrode. All these results are in agreement with the ionophore character of the thyomacrocycle compound with respect to $\mathrm{Cu}(\mathrm{II})$ ions, previously observed $[12,13]$.

\section{Acknowledgements}

This work has been supported by the MCYT through project CTQ2004-08046C02. The authors thank Dr. A. Errachid and group of Prof. J. Casabó for kindly providing the thiomacrocyclic compound.

\section{References}

1. M.C. Petty, Langmuir-Blodgett Films: An Introduction, Cambridge University Press UK, 1996.

2. A. Ulman, An Introduction to Ultrathin Organic Films, Academic Press, Boston, 1990.

3. $\quad$ L.M. Goldenberg, J. Electroanal. Chem. 379 (1994) 3-19.

4. S. Boussaad, L. Dziri, R. Arechabaleta, N.J. Tao, R.M. Leblanc, Langmuir 14 (1998) 6215-6219.

5. K. Wohnrath, J.R. Garcia, F.C. Nart, A.A. Batista, O.N. Oliveira Jr, Thin Solid Films 402 (2002) 272-279.

6. M.F. Mora, N. Wilke, A.M. Baruzzi, Langmuir 19 (2003) 6876-6880.

7. F. Yin, H-K. Shin, Y-S. Kwon, Biosens. Bioelectron. 21 (2005) 21-29.

8. S. Martin, A. Villares, M. Haro, M.C. López, P. Cea, J. Electroanal. Chem. 578 (2005) 203-211.

9. J. Cabay, J. Sotoducho, A. Nowakowska, A. Chyla, Electroanalysis 18 (2006) 801-806.

10. S.Y. Heriot, Hao-Li Zhang, S.D. Evans, T.H. Richardson, Colloids Surf. A: Pysicochem. Eng. Aspects 278 (2006) 98-105. 
11. J. Torrent, M. Pla, L. Escriche, J. Casabó, A. Errachid and F. Sanz, J. Colloid Interf. Sci. 301 (2006) 585-593.

12. I.A. Marques de Oliveira, M. Pla-Roca, Ll. Escriche, J. Casabó, N. Zine, J. Bausells, J. Samitier, A. Errachid, Mater. Sci. Eng. C 26 (2006) 394-398.

13. I.A. Marques de Oliveira, J. Torrent-Burgués, M. Pla, N. Zine, J. Bausells, Ll. Escriche, J. Casabó, A. Errachid, J. Samitier, Anal. Lett. 39 (2006) 1709-1720.

14. E. Guaus and J. Torrent, Russ. J. Electrochem. 42 (2006) 141-146.

15. Stability Constants of Metal-ion Complexes, Special Publication No 17, The Chemical Society, London 1964.

16. D. Grujicic and B. Pesic, Electrochim. Acta 47 (2002) 2901-2912.

17. A.J. Bard, L.R. Faulkner, Electrochemical Methods: Fundamentals and Application, $2^{\text {nd }}$ ed. John Wiley and Sons (2001).

18. C. Gabrielli, P. Moçotéguy, H. Perrot and R. Wiart, J. Electroanal. Chem. 572 (2004) 367-375.

19. J.-P. Diard and C. Montella, J. Electroanal. Chem. 590 (2006) 126-137.

20. A. Milchev, T. Zapryaanova, Electrochim. Acta 51 (2006) 2926-2933.

21. A.I. Danilov, E.B. Molodkina, Yu.M. Polukarov, V. Climent and J.M. Feliu, Electrochim. Acta 46 (2001) 3137-3145.

22. A. Ramos, M. Miranda-Hernandez, I. Gonzalez, J. Electrochem. Soc. 148 (2001) C315-321.

23. H.O. Finklea in: A.J. Bard, I. Rubinstein (EDS.), Electroanalytical Chemistry, vol. 19, Marcel Dekker, New York, 1996.

24. J.J. Calvente, G. López-Pérez, P. Ramírez, H. Fernandez, M.A. Zón, W.H. Mulder, R. Andreu, J. Am. Chem. Soc. 127 (2005) 6476-6486.

25. M. Zhang, C. Mullens, W. Gorski, Electrochim. Acta 51 (2006) 45284532.

26. M. Topçu, Ö. Gökdogan, A. Gülce, H. Gülce, Biosens. Bioelectron. 21 (2006) 1719-1726. 